\title{
Arqueología del alto río Guachicono: ocupación prehispánica vertical en el macizo colombiano
}

María Eugenia Orejuela M.*

RESUMEN

LA OCUPACIÓN PREHISPÁNICA EN LA CORDILLERA DE LOS ANDES HA SIDO UN TEMA DE INTERÉS EN LAS INVESTIGACIONES DIRIGIDAS AL USO DEL ESPACIO EN DISTINTOS PISOS TÉRMICOS. ESTE TRABAJO FUE REALIZAdO EN LOS AÑOS DE 1995 y 1996 en el Macizo Colombiano. La etnohistoria en relación al dato arqueológico, desde donde parte ESTA INVESTIGACIÓN, SUGIERE PODER CONTRASTAR Y PONER A PRUEBa AMBAS POSTURAS, LA ARQUEOLOGÍA Y LA ETNOHISTORIA. SE LOGRÓ OBSERVAR EN EL PAISAJE A 3.300 M.S.N.M, CONCENTRACIONES DE TERRAZAS ESCALONADAS,

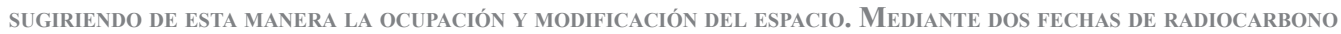
SE CONSTATÓ El CARÁCter PREHISPÁNICO DE LAS TERRAZAS. EsTa OCUPACIÓN FUE MENCIONADA EN LOS DATOS etNohistóricos dejados por los CRonistas a su paso por el Macizo Colombiano.

Palabras claves: piso térmico - etnohistoria - arqueología - uso del esPacio - Paisaje.

\section{Abstract}

The prehispanic occupation of the Andes mountain range has been an interesting theme in research into USE OF SPACE AT DIFFERENT TEMPERATURE ZONES. THIS WORK WAS CARRIED OUT IN THE YEARS OF 1995 AND 1996 ON the Colombian Massif. The ethno-history in relation to the archaeological Data suggests that we can CONTRAST AND TEST BOTH THE ARCHEOLOGICAL AND ETHNO-HISTORICAL APPROACHES. LADDERED TERRACES WERE OBSERVED AT AN ALTITUDE OF 3,300 METERS, SUGGESTING THIS PARTICULAR OCCUPATION AND MODIFICATION OF SPACE. THROUGH RADIOCARBON DATING, THE PREHISPANIC NATURE OF THE TERRACES WAS CONFIRMED. THIS OCCUPATION WAS



KEYWORDS: THERMAL FLOOR - ETHNOHISTORY - ARCHEOLOGY - USE OF SPACE - LANDSCAPE.

* Antropóloga y arqueóloga. Investigadora independiente. Maestría en Arqueología y Prehistoria. PhD (C) en Arqueología y Prehistoria Universidad Autónoma de Barcelona. Correo electrónico: mariaeugeniaorejuela@gmail.com 


\section{Introducción}

$\mathrm{U}$ na característica de los Andes centrales y septentrionales fue la ocupación y modificación del espacio. Este se ve representado en la concentración de terrazas en laderas para vivienda, el acceso a recursos y el uso del espacio en "vertical". Este patrón de ocupación ha sido un tema en las investigaciones acerca de la complementariedad entre distintos pisos térmicos estudiada por Humboldt (1931), Troll (1958), Murra (1972 [2014]) y Oberem (1981). Se ha demostrado que una de las principales estrategias de ocupación del espacio de los grupos prehispánicos andinos e interandinos fue la explotación simultánea o interdigitada de varios pisos ecológicos desde las tierras altas hasta las bajas. Durante las últimas décadas las teorías frente al uso del espacio han desarrollado propuestas en el análisis del paisaje y en relación a la arqueología (Orejas, 1991; Anschuctz, Wilshusen y Scheick, 2001; Langebaek y Dever, 2009; Sánchez, 2010; Gómez, 2011; Patiño, 2013; Ruíz, 2015; García, 2016). Se ha demostrado que el interés por el paisaje y el uso del espacio poseen datos importantes acerca de los cambios sociales. También se considera que existe un vínculo con el paisaje y una estrecha relación simbólica acudiendo a las propuestas postmodernas; donde la relación entre sociedad y paisaje conllevan a una puesta en escena del pensamiento expresado en el espacio. Así que las investigaciones arqueológicas, ecológicas y etnohistóricas en los Andes centrales y septentrionales indican que los grupos humanos desarrollaron diversos mecanismos que permitieron el acceso a recursos de diferentes pisos térmicos, basados en dispositivos institucionales desarrollados a partir de diversos sistemas de descentralización y centralización (Troll, 1931; Murra, 1972[2014]; Oberem, 1981; Salomon, 1985; Langebaek, 1992), y en mecanismos tecnológicos, políticos y sociales que permitieron el intercambio de productos y el control de uno o varios pisos térmicos. En Perú y Bolivia se ha planteado el control vertical como un patrón de asentamiento centralizado con la disposición de colonias a larga distancia, permitiendo el acceso a recursos de diferentes en distintos pisos térmicos Murra (1972 [2014]).

Oberem (1981) sugirió que el modelo de Murra sólo era aplicable a pisos amplios, y la complementariedad ecológica en los Andes septentrionales podría ser mejor entendida como "microverticalidad", es decir, mediante el acceso a diferentes pisos localizados a distancias cortas (Salomon, 1985). De igual manera Rostowrosky (1976) consideró la relación de los pueblos de la costa del Perú con las tierras Altas. Al respecto Langebaek (1995) sugiere que en Colombia se ha hablado de complementariedad ecológica sin evidencias suficientes y sin saber si es o no importante para las sociedades que se estudian. El autor plantea para los Andes colombianos un patrón de poblamiento móvil, ya que estos son más estrechos y el desplazamiento se hace desde unidades domésticas con autonomía en recursos básicos (Langebaek, 1992:113). En Colombia en los últimos años se han realizado trabajos enfocados hacia la modificación del paisaje en el suroccidente colombiano (Langebaek y Piazzini, 2003; Patiño, 2013; Ruíz, 2016). La relación entre paisaje y cambio social se halla también articulada con las catástrofes naturales (Patiño, 2013; Ruíz, 2016).

Este trabajo trató de avanzar desde dos temas a partir de la concentración de ocupación prehispánica en el Macizo Colombiano (Cordillera Central), y la ocupación de varios pisos térmicos observados desde la arqueología y descritos en los datos etnohistóricos. Se ha considerado que la etnohistoria y la arqueología como dos disciplinas complementarias (Salomon, 1980: 36) pueden ser contrastadas. Esta investigación se llevó a cabo en la parte alta del río Guachicono Departamento del Cauca Colombia. Mediante restos arqueológicos se planteó probar una formulación etnohistórica: a) la relación entre los llamados Guachicono "caliente" y Guachicono "frío" (Romoli, 1962: 245), b) entender posibles mecanismos de complementariedad usados por las comunidades prehispánicas de esta parte de Los Andes. El reconocimiento arqueológico no sistemático se llevó a cabo en la parte alta y media del río. Los datos obtenidos fueron contrastados con el trabajo realizado en la parte baja del río por Patiño y Gnecco (1986). Estas comparaciones intentaron demostrar una ocupación 


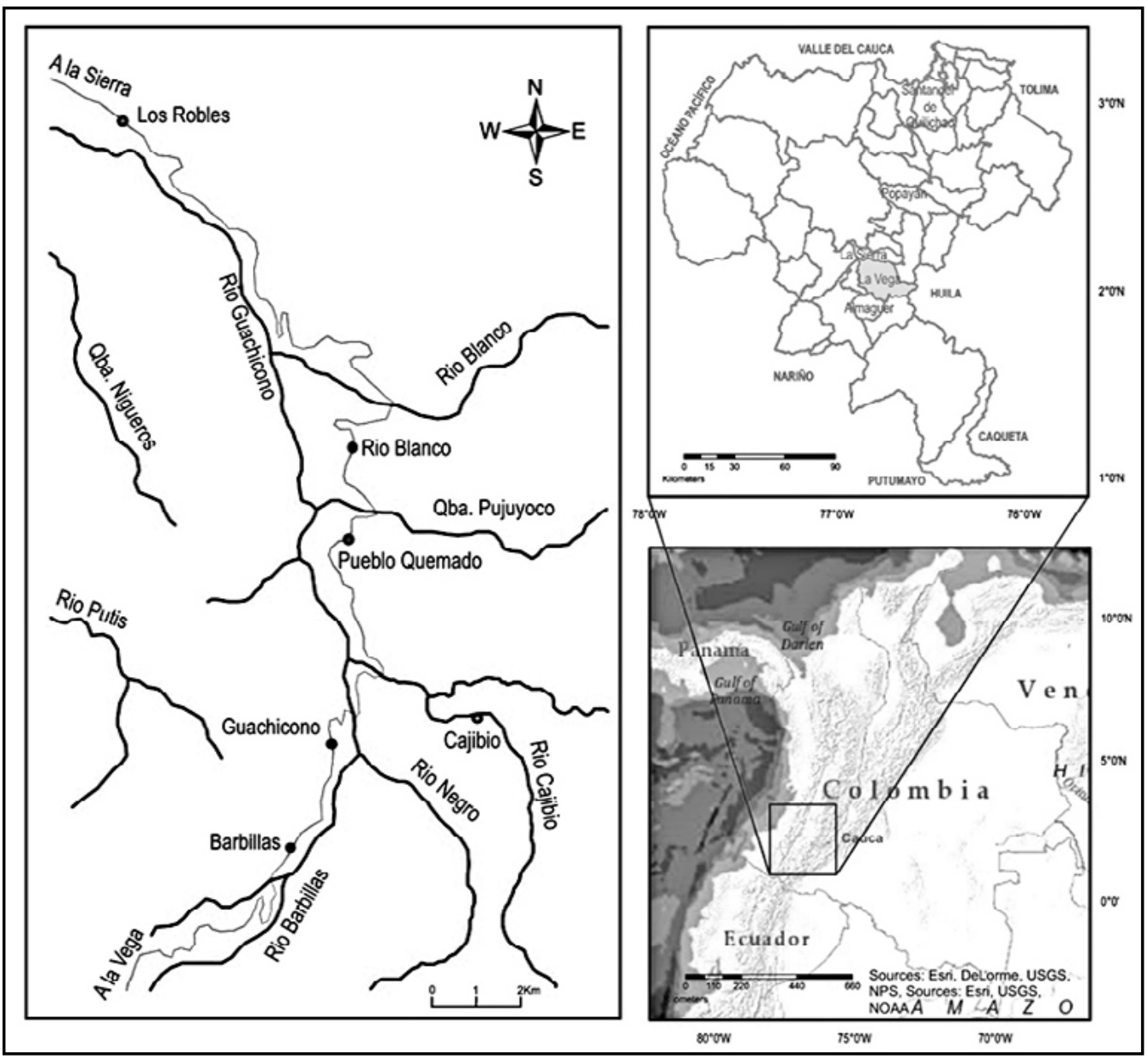

MAPA 1. LOCALIZACIÓN DEL ÁREA INVESTIGADA. 
prehispánica desde los 3.000 m.s.n.m., donde se ubica el resguardo de Guachicono, hasta 1.700 m.s.n.m., en la comunidad indígena del Moral. La cerámica no fue el único indicador de ocupación, también se registraron modificaciones del paisaje como terrazas escalonadas de forma semi circular y petroglifos.

\section{Contexto geográfico y área de investigación}

El Macizo Colombiano, de donde se desprende la cordillera Oriental, posee una tercera unidad geográfica que es la Amazónica (IGAC, 1993)․․ Éste evolucionó a partir de eventos metamórficos y magmáticos ligados con la zona de subducción del pacifico con la formación de altiplanos ocupados por lagos que posteriormente fueron sedimentados y hoy conocidos como los altiplanos de Paleteará y Páramo de las Papas. El eje volcánico activo de los conucos con gran actividad explosiva y efusiva, constituye uno de los elementos dominantes y de mayor dinámica dentro de la diversidad paisajística (IGAC, 1995). En el Macizo Colombiano existen cerca de 360 lagunas y nacen las cuatro arterias fluviales más importantes del país en diferentes direcciones: Magdalena y Cauca hacia el Norte, Putumayo y Caquetá hacia el Sudeste y Patía hacia el Suroeste. La distribución altitudinal de la vegetación permite la presencia de bosque subandino, andino, alto andino y páramo ${ }^{2}$.

\section{Etnohistoria y arqueología en el alto Guachicono}

El Macizo Colombiano se ha estudiado desde la etnohistoria Romoli (1962); la antropología Zambrano (1991); la historia Buenahora (1997); la arqueología Patiño y Gnecco (1986); Orejuela (1998); Nuñez (2000); Ortiz (2001); Márquez (2006); Giraldo (2007); Burbano (2016).

Las distintas visitas realizadas al suroccidente del país en el siglo XVI (Céspedes, 1983; Tovar, 1993) se refieren constantemente a la Provincia de Almaguer que correspondería a lo que hoy se conoce como Macizo Colombiano. Esta provincia fue dividida en tres partes: (a) Mamendoy, (b) la loma de los Humos y el valle de las Papas, y (c) Guachicono. Esta última fue la más importante de las tres y estaba conformada por las cuencas de los ríos Guachicono, Pancitará y San Jorge (Romoli, 1962) (Mapa 1). Además de los pueblos mencionados, aparecen tres independientes: Cacaoña, Ytopan, y Choa (Romoli, 1962:246). Estas visitas establecieron una diferencia administrativa. Llamaron "Guachiconu" a los pueblos que ocuparon la parte alta del río Guachicono, y llamaron "calientes de Guachicono" a los que habitaban el curso inferior del río (Ibíd.). Los primeros eran tasados con productos de clima frío (mantas de lana, trigo) y los segundos con productos de tierra caliente (mantas de algodón, maíz). El trigo fue introducido a América y su domesticación tuvo que ser un proceso a largo plazo, luego es posible que las tasaciones se hicieran inicialmente con algún tipo de cultígeno, como la papa o la quinua. De tal manera, el hecho de que el patronímico usado sea el mismo puede obedecer simplemente a que los grupos recibieron indistintamente, el nombre del río. Romoli menciona que los caciques recibían el nombre del lugar donde mandaban y viceversa (Ibíd.).

Esta investigación consideró que la diferenciación fuese puramente administrativa es decir, que todo el curso del río Guachicono estuviese poblado por un mismo grupo étnico, y que los diversos pisos térmicos fueran explotados a través de algún mecanismo de complementariedad, pero también planteó que esta diferenciación tuviese raíces prehispánicas y que se tratase de etnias distintas. Por su parte Romoli (1962) dice que no hay una identidad étnica en la lingüística preservada en los documentos coloniales entre los "calientes de Guachicono" y los "Guachiconu" de la parte alta del río (fríos). La denominación de "provincia" hecha por los españoles hacía

1 Instituto Geográfico Agustín Codazzi (IGAC).

2 http://documentacion.ideam.gov.co/openbiblio/bvirtual/005192/macizo/pdf/capitulo1.pdf. [Recuperado, 27 de noviembre de 2017]. 
referencia a "gente de una misma raza, lengua o grupo étnico" (Romoli, 1962: 244) asociados a un mismo poblado o aldea. En los estudios de etnohistoria se ha observado que los "pueblos de indios" se conformaban por varias familias y bajo la dirección de un jefe o un cacique. Por consiguiente "provincia" era la unidad mayor formada por varios "pueblos de indios" o cacicazgos bajo la dirección de un "cacique principal" o "señor" al cual tributaban varios caciques secundarios (Romoli, 1962: 246). Buenahora (1997) ${ }^{3}$ menciona que "cacique" fue un término adoptado por los conquistadores del Caribe para facilitar sus "relaciones" con los jefes tribales, a su vez fueron llamados Kuracas en Ecuador y Perú. En Colombia el término fue introducido por Hernán Trimborn en 1949 (en Ibíd.). Así las denominaciones de "poblado" "pueblos de indios" y "provincia" hacen parte de la organización espacial española para fines administrativos. Luego provincia hace parte de la construcción de frontera hecha por los españoles.

La frontera es "como la transición entre dos o más territorialidades. Territorios donde predominan formas culturales como la militar, la misional, de economía extractiva, la comercial, la minera y la agrícola. De esta manera en caso de darse una consolidación de la territorialidad se establecen las fronteras móviles y las fronteras fluidas en sociedades equiparables en términos militares y políticos (...)” (Vargas, 1993: 39). A su vez Ramírez (1996:134) menciona que “(...) es indiscutible la existencia de una compleja estructura de relaciones económicas, políticas y territoriales de los grupos del piedemonte en su situación de frontera, lo cual también les permitió establecer relaciones con los grupos andinos". En cualquier caso las crónicas tempranas indican la existencia de mecanismos de movilidad para la adquisición de recursos. Al respecto un anónimo comenta: "Alcanzan algunos valles calientes, donde de algodón cogen cantidad y de coca y de yuca, y mucha cantidad de maíz dos veces en el año, que en lo frio no se da más que una" (anónimo, Relación de Popayán y del Nuevo Reino 1559-1560).

La parte Sur de la provincia de Almaguer, entre el río Mayo por el Sur y el cacicazgo de Mamendoy del Pueblo de la Cruz por el Norte (Ramírez, 1995) fue asiento según la denominación colonial de los pueblos Quillacingas más septentrionales. Los Quillacingas y los Pastos fueron mencionados inicialmente por Cieza de León en 1540 luego, posteriormente nombrados de manera más detallada por las visitas de López en 1558-1559 y la de García de Valverde en 15701571. López (1558-1559) dividió la provincia de los Quillacingas interandinos en Quillacingas camino a Quito, Quillacingas camino a Popayán, Quillacingas del valle de Pasto y Quillacingas camino a Almaguer. Los pueblos que ocuparon esta región incluidos los Quillacingas fueron catalogados como "behetrías". Término que hace referencia a grupos sin reconocimiento de autoridad permanente sin caciques ni señores pero que en condiciones de guerra o de conquista tenían un cierto sentido de "resistencia" (Friede, 1953: 100-101; Buenahora, 1997: 50). Así una relación anónima (Ramírez, 1995:46) dice que la provincia de Almaguer: no hay cacique ni señores e así todo es behetría. Sin embargo, de la provincia de Guachicono se dice que: "Es tierra fria y en ella ay un señor principal que la manda toda y le obedecen. La de Pansitara es tierra fria y que tiene muy junta su poblazon" (Anónimo, 1560, en Ramírez, 1995: 47).

En la lista de antroponímicos mencionada por Romoli (1962) se hallan los nombres de los señores principales o caciques de Guachicono y Pancitará. Estos dos grupos carecían para los españoles de las características que hacían referencia a la "behetría". De ello se concluiría que la provincia de Almaguer en el siglo XVI estaba poblada por grupos organizados ya fuese bajo el nombre de "behetría" o de "cacicazgo", como los de Guachicono "frío" y Pancitará. Estas formas de organización independientemente de cómo fueron catalogadas por los españoles, son supuestos de partida en esta investigación sobre cierta adecuación del espacio. Así el dato arqueológico, como el registro de sitios, terrazas usadas para vivienda, cultivo, tumbas

3 "Los cacicazgos eran agregaciones de personas organizadas a través del parentesco, de tamaño e importancia diferenciada que compartían un patrimonio territorial y obedecían a un "jefe" que sobresalía en un examen a simple vista, poseían la misma lengua y las mismas estructuras simbólicas alrededor de sacerdotes o chamanes. A la cabeza de los clanes, y soportando de primera mano el poder del cacique, había hombres prominentes a quienes los españoles llamaron "señores principales" o "principales" a secas" (Buenahora, 1997: 15). 
y basureros pueden mostrar dicha ocupación en la zona de estudio en la parte alta y media del río Guachicono, para luego ser contrastadas con el dato etnohistórico. De esta manera se le da continuidad a la propuesta hecha también por Cárdenas (1996: 42) cuando menciona "(...) que los datos etnohistóricos sean los fundamentos para plantear hipótesis acerca de las sociedades del pasado que deban comprobarse mediante el registro arqueológico". Esta investigación partió del dato etnohistórico para ser sustentada en el dato arqueológico a través de la verificación de ocupación prehispánica en la parte alta y media del río Guachicono (Mapa 1).

\section{Trabajo de campo y metodología}

Este trabajo se llevó a cabo en dos resguardos Yanaconas del Alto río Guachicono y la comunidad indígena El Moral de la parte media abarcando un área total aproximada de $24.5 \mathrm{~km}^{2}$. Los resguardos Guachicono y río Blanco están ubicados en la parte alta del río y la comunidad indígena de El Moral está localizada en la parte media del río. La altura del área investigada oscila entre los 3.300 y 1.700 m.s.n.m. El reconocimiento arqueológico se realizó de manera no sistemática iniciándose en Barbillas en el resguardo de Guachicono a 3.300 m.s.n.m. y extendiéndose hasta las veredas de Robles y Santa Marta a 1700 m.s.n.m., que pertenecen a la comunidad indígena de El Moral. Se utilizaron planchas y fotografías aéreas para registrar los hallazgos. Así como se realizaron recolecciones superficiales en caminos y cultivos, pozos de sondeos de 50 × 50 metros hasta el cambio de estratigrafía. Los sondeos se realizaron en sitios donde pudiese existir algún tipo de evidencia arqueológica como planadas, terrazas y montículos. Asimismo, se hicieron dos cortes de $1 \times 1 \mathrm{~m}$. en un basurero ubicado en un plan de la vereda la Floresta (río Blanco) y en una terraza en la vereda de río Negro (Guachicono) (Mapa 1). La profundidad de los cortes alcanzo los $80 \mathrm{~cm}$.

\section{Los hallazgos arqueológicos}

La concentración de terrazas dispuestas de manera escalonada se observó claramente en Barbillas y río Negro, ambos en el resguardo de Guachicono en la parte alta del río. El tamaño promedio de las terrazas ${ }^{4}$ varía entre $\operatorname{los} 6$ x 4 y 5 x 10 metros. Las terrazas grandes tienen un promedio de hasta $40 \times 15$ metros y dos de ellas $70 \times 15$ metros aproximadamente. Con frecuencia se encuentran grupos de terrazas rodeando una de mayor tamaño en los resguardos de río Blanco y Guachicono. Su estructura semi circular es idéntica a los aterrazamientos prehispánicos reportados para todo el suroccidente colombiano (Uribe, 1978; Llanos, 1988; Herrera, 1990; Cardale, et al., 1992; Patiño, 1994). En el corte exploratorio realizado en la terraza de la vereda río Negro se recuperó una muestra de carbón que arrojó una fecha de $1070 \pm 80 \mathrm{AP}$ (Beta-109707) que confirma el carácter prehispánico de estas estructuras. Parte del resguardo de Guachicono se encuentra sobre un paisaje antrópico prehispánico en el que se ubicaron 163 terrazas para un total de 223 terrazas. Esta observación también fue hecha en Caquiona (Romoli, 1962: 281), pueblo situado muy cerca del área de estudio.

Los "bohíos" rodeaban generalmente una construcción más importante, como la sede religiosa o política. Para los españoles un "poblado" era toda una extensión construida o cercada que podía tener grandes dimensiones y en el interior varias casas o "bohíos" ocupadas simultáneamente en las "poblazones" y otras cerca de los cultivos (Arango, 1989:27). Al respecto en el siglo XVI se observó “(...) la provincia de Guachicone muy poblada (...)”(Cieza de León 1971:134). Por el número de terrazas pareciere que ello se confirma. En el resguardo de Río Blanco la densidad de terrazas disminuye pero su distribución y forma son iguales a las del resguardo de

4 En esta investigación se hace referencia a la modificación del terreno para uso de vivienda, en sitios de ladera. La forma consiste en un corte en el terreno para aplanar o moldear el sitio, quedando en planta de forma semicircular.

5 Los "bohíos" fueron descritos por los españoles como de forma circular. 
Guachicono. Una fecha de $530 \pm 60$ AP (Beta- 109706) obtenida en un pequeño basurero en la vereda La Floresta también confirma el carácter prehispánico de la ocupación. En el sector de El Moral disminuye la cantidad de material cerámico y de hallazgos. La intensidad de la ocupación disminuye a medida que se desciende por el cañón del río Guachicono. Estas evidencias en la zona de sub-páramo en alturas de más de 3.000 m.s.n.m, se encuentran relacionadas con la información etnohistórica que indica que el territorio de Almaguer fue habitado tanto en las zonas accesibles como en las altas serranías con preferencia en los páramos (Romoli, 1962: 245). De igual manera, los trabajos arqueológicos realizados en el Valle de las Papas y en Santa Rosa Alto Caquetá reportan construcciones similares en menor cantidad. Nuñez (2000) reporta una fecha (890 \pm / 60 A.P) para el Valle de las Papas y Ortiz (2001) una fecha (1040 \pm 70 BP) en Santa Rosa, ambas recuperadas en excavaciones en extensión de terrazas. Estas dos fechas se encuentran relacionadas con las fechas del Alto Guachicono.

En el valle del río Guachicono y del Patía los asentamientos se localizan en los valles de cada río (Patiño y Gnecco, 1992: 80), donde algunos sitios como el Mirador tuvieron una disposición nucleada en terrazas aluviales (Patiño, 1982). En cuanto a las prácticas funerarias los entierros primarios están en tumbas de pozo poco profundas de 1 a 1.5 metros, y los secundarios en grandes urnas. En el valle del Guachicono ésta es una de sus principales características y fueron diferenciados en entierros de "élite" y entierros "comunes". Los primeros asociados a la mayor elaboración de la tumba y a un numeroso ajuar funerario; los segundos se hallan en mayor cantidad y son poco elaborados (Patiño y Gnecco, 1992: 80-83). Sin embargo, en la parte alta y media del río Guachicono se registraron tumbas saqueadas. En la vereda de Cajibío (resguardo de Guachicono) a cuatro kilómetros al norte de Barbillas, se localizó sobre una zona plana un sitio con un montículo natural modificado y cuatro petroglifos. Estos junto con los registrados en la escuela de la misma vereda y en el resguardo de Río Blanco, muy cerca del cauce del río, son figuras en espiral las cuales también se hallan en la vereda Campo Bello (El Moral) sobre el cañón del Guachicono en la parte baja, Oscar Jiménez (comunicación personal, julio de 1996). Estas figuras ya han sido documentadas en Nariño por (Grot y Hooykas, 1991: 83). De igual manera también se han registrado en Bolívar Cauca (Burbano, 2016: 105).

\section{Restos botánicos}

Acerca de los restos botánicos las crónicas mencionan lo observado en la provincia del Collao Perú ubicada en tierras altas al igual que Guachicono:

“(...) cogen también una semilla que llaman quinuá, que se cría en unos arbolillos como cenizos de España, sino que son más altos: es la semilla muy menudita; estos siembran a sus tiempos y muchas veces se les hiela. Comen algún maíz de Los valles que tienen a la parte de la mar del sur, y otros que están en Los Andes hacia la mar del norte, de rescate con la lana y ganados que tienen éstos mucho" (Pizarro, 1571, en Morlon, 1996: 120).

En las muestras de suelos tomadas en las excavaciones exploratorias en el sitio La Floresta entre 50 y $60 \mathrm{~cm}$. de profundidad (resguardo de río Blanco) se recuperó mediante el método de trilla y selección manual semillas de quinua (Chenopodium quinuoa), Cyperacea, Psidum $s p$ y Rubus sp (mora silvestre), Capsicum (ají) las cuales fueron comparadas a nivel genérico ${ }^{6}$. La quinua recuperada en este caso son semillas parcialmente domesticadas o silvestres, la cyperaceae es una planta silvestre que normalmente crece en zonas anegadizas y humedales. El psidum $s p$ es una guayabita de semilla pequeña y traslúcida con embrión curvo en el interior, esta forma es andina. El Rubus $s p$ es una mora silvestre y el Capsicum (ají) es preferiblemente de tierras altas existen silvestre y cultivado. Estas semillas están relacionadas con la fecha de

6 Identificadas por Roberto Tulio González (biólogo botánico Universidad del Valle, Cali Colombia). 
radiocarbono en el sitio La Floresta 530 \pm 60 AP (Beta - 109706) este dato confirma el uso del suelo en tiempos prehispánicos y a su vez se articula con el dato etnohistórico.

\section{La alfarería y relaciones}

La mayor cantidad de material cerámico recuperado fue clasificado en siete tipos, proviene de recolecciones de superficie con una muestra de 1.400 fragmentos. Este material se clasificó bajo criterios de pasta, superficie, decoración y forma. Se usó el método comparativo para encontrar similitudes o diferencias entre dos zonas o más (Nuñez-Regueiro, 1984: 20). Los cortes realizados en La floresta y en río Negro presentan una distribución de la cerámica que permite no solamente inferir continuidad alfarera sino cronológica entre ambos sitios. Para el bajo Guachicono la tipología está planteada sobre dos fases secuenciales; la fase Alto Patía con los tipos, Inciso impreso que es el más representativo, Patía Café Arenoso sin pintura, y la fase Guachicono con tres tipos cerámicos pintados que son: Rojo/Crema, Policromo, Pintura Roja y dos tipos cerámicos sin decoración Café Arenoso y Rojo Friable (Patiño y Gnecco, 1992: 72-76). La tipología hecha para el Alto Guachicono se ha denominado Río Blanco para diferenciarla de la cerámica del valle del río Guachicono. Se encontró alguna relación con el tipo Rojo/Crema por Cadavid y Ordóñez (1992: 120). La mayor cantidad de cerámica recuperada se halló en la parte alta de río en el resguardo de Guachicono (Gráfico 1). Las formas globulares y cuencos con bordes invertidos y evertidos de labios redondeados y planos tienen semejanzas con las zonas aledañas del valle del Patía y la zona baja del río Guachicono. De igual manera Nuñez (2000: 42) registró para el Valle de las Papas un fragmento con aplique similar al registrado en la parte media del río Guachicono.

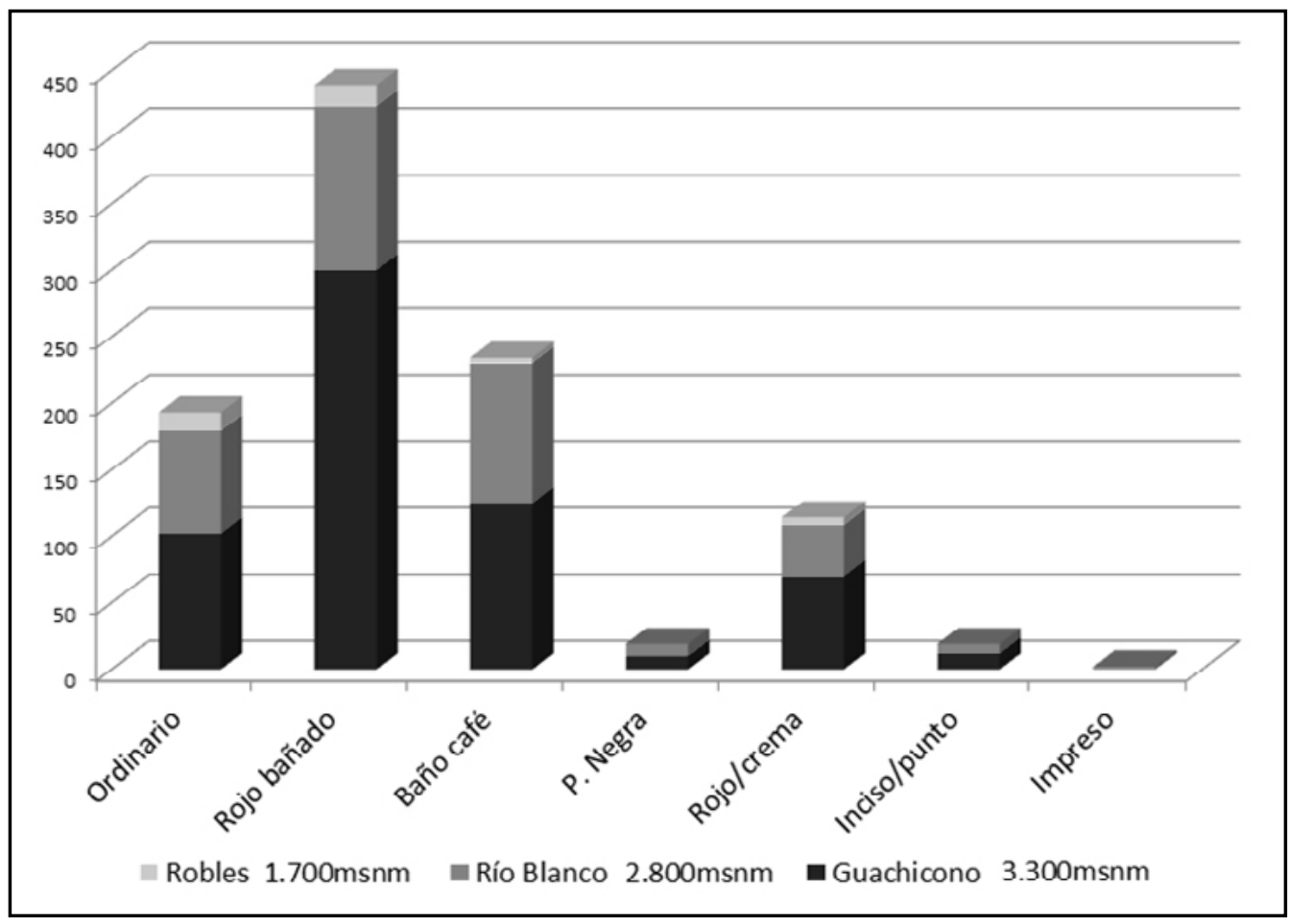

GRÁFiCO 1. Distribución de la CERÁmica en RElación a la Altitud. (Elaborado por la autora) 
Una forma con perforación encontrada en Robles se comparó con el yacimiento arqueológico de San Agustín (Duque y Cubillos, 1981: 48-49). Estas características observadas no son variables claras para asegurar relaciones entre la zona de estudio y sitios aledaños; pero tampoco descartan que el sitio de investigación haya estado conectado con las áreas cercanas. El análisis petrográfico realizado a la cerámica del Alto Guachicono en Ingeominas (Popayán, julio de 1997) ${ }^{7}$ indica que el desgrasante usado y la arcilla de materia prima son locales. Esta producción local sugiere una autonomía en lo que se refiere a productos tan básicos como la cerámica. En general se trató de cerámica de uso doméstico.

\section{Discusión}

La división de los Guachiconos "fríos" y los "calientes" de Guachicono fue hecha con propósitos administrativos. El nombre del río fue puesto indistintamente para diferenciar administrativamente a sus habitantes. Los datos etnohistóricos mencionan que Guachicono se diferenciaba por tener: "El señor cacique principal que llamamos Guachiconu e por otro nombre se llama Gitun" (Romoli, 1962: 245). Estas observaciones etnohistóricas parecen indicar que la formación social de la población de Guachicono "frío" no era de las llamadas "behetrías" aunque los poblados de Barbillas y Río Negro ubicados en la parte alta del río pueden ser indicadores de patrones de concentración demográfica característicos de las formaciones cacicales; sin embargo la información no es suficiente para asegurarlo. Las fechas obtenidas permitieron sugerir, contemporaneidad en el poblamiento prehispánico del Alto y del Bajo Guachicono/Alto Patía, donde Patiño y Gnecco (1992) determinaron dos fases con fechas de $870 \pm 60$ AP (Beta-10766), y $480 \pm 110$ AP (Beta-10765). De igual manera Nuñez (2000) reporta una fecha (890 \pm / 60 A.P) para el Valle de las Papas y Ortiz (2001) una fecha (1040 \pm 70 BP) en Santa Rosa. La alfarería de las dos zonas Alto y Bajo Guachicono necesitaría de trabajos más puntuales para esclarecer diferencias o similitudes. Sin embargo, la alfarería del Alto Guachicono también se relaciona escasamente con San Agustín y Tajumbina y esto probablemente significa que existieron relaciones en varias direcciones, por el corredor del Guachicono hacia Patía, por el Macizo hacia Nariño, por el Alto Magdalena, Alto Caquetá hacia el piedemonte amazónico (Ramírez, 1996). Gnecco (2003: 13-14) menciona para el Alto Caquetá que no existen evidencias claras de esta relación entre tierras Altas y bajas. De esta manera Gnecco (2003: 37) considera “(...) la circulación de ideas y de ciertos bienes (...)". Por su parte Giraldo menciona que en el análisis de activación de neutrones (AAN) no existen pruebas sólidas de cerámica extranjera en el área del Alto Caquetá. Este autor también sostiene que el tipo cerámico corrugado se ha utilizado para sugerir interacción entre las tierras altas y bajas (en prensa). Sin embargo Gnecco en el Alto Caquetá encuentra un porcentaje muy bajo de este tipo $(\mathrm{Ibíd})^{8}$. Las similitudes o imitaciones de tipos cerámicos bien pueden sugerir las relaciones o la circulación de ideas como bien menciona Gnecco (2003). En las relaciones entre zonas aledañas a cortas o largas distancias en regiones multiétnicas lo que pudo haber viajado fue la técnica, con la intención de elaborar una tipología de cerámica en particular (Orejuela, 2016).

La concentración de terrazas se encuentra localizada en la parte alta de los resguardos de Guachicono y Río Blanco con la mayor concentración a los 3000 m.s.n.m. Se debe considerar que los datos etnohistóricos mencionan el pueblo de "Zotara" (Cieza de León, 1971: 134). Este pueblo bien hubiese podido ser el actual Pueblo Quemado que hoy día hace parte del resguardo de Río Blanco y se encuentra en las faldas del volcán Sotará. La ocupación de las partes altas puede obedecer a las tierras fértiles aptas para cultivar papa y quinua como elementos de intercambio. La altura no ha frenado la ocupación humana en los Andes y "las limitaciones están mucho más

7 Actual Servicio Geológico colombiano (SGC).

8 Traducción propia. 
ligadas a las posibilidades de ejercer actividades productivas" (Dollfus, 1991: 56). La elección de un cultivo puede obedecer a formas rituales no solamente al uso de suelos fértiles (Ibíd.). El Macizo Colombiano ha sido un sitio de paso (Romoli, 1962), los caminos pueden haberse modificado con el uso y el paso del tiempo, pero aún sirven como red de comunicación. Sin embargo, se ha mencionado que el intercambio cultural y económico a través de este trecho de los Andes fue insignificante en tiempos precoloniales (Friede, 1947: 37). Las concentraciones de terrazas en la parte alta del curso del río Guachicono por encima de 3.000 m.s.n.m, conforman verdaderos poblados. Uribe (1978) logró documentar nucleación prehispánica en el altiplano de Nariño; Llanos (1995) en el alto Magdalena; Salgado, Rodríguez y Bashilov (1993) en Calima; Langebaek (1998) en Tierradentro. La aldea registrada en Inza Tierradentro esta datada en el período tardío y se relaciona con suelos fértiles es decir acceso a recursos. De igual manera la aldea de esta investigación guarda esas dos características: ocupación tardía y suelos fértiles. En cuanto al patrón de poblamiento disperso, se ha sugerido, con los datos obtenidos hasta el momento para el suroccidente colombiano, que la dispersión indígena se produce por la llegada de los españoles como menciona Romoli (1962: 255-258).

\section{Conclusión}

De acuerdo con los datos arqueológicos y etnohistóricos el curso del río Guachicono fue ocupado por grupos que posiblemente interactuaban. La presencia de aterrazamientos demuestra que Guachicono "frío" si fue muy poblado, lo mismo sucede con Pancitará, la loma de los Humos y Caquiona ya mencionado desde la etnohistoria por Romoli (1962: 281). Los trabajos realizados acerca de complementariedad desde la etnohistoria en otros sitios cercanos a la zona de estudio como es el caso del piedemonte Amazónico y el Norte del Ecuador (Ramírez, 1995; Salomon, 1985), proponen un intercambio económico y cultural generalizado en el Norte de los Andes. La diferencia entre los guachiconos "fríos" y "calientes" fue administrativa. Ahora bien, si se trataba de un mismo grupo ocupando todo el curso del río, los datos arqueológicos hasta el momento son escasos para afirmarlo. Las semillas de quinua recuperadas no son suficientes para asegurar que fue producto de intercambio y de cierta especialización; estas dan cuenta del uso del suelo en tiempos prehispánicos en el Alto río Guachicono. Hasta el momento no se puede afirmar más que la ocupación y uso del espacio de manera "vertical" en tiempos prehispánicos, coloniales y actuales.

\section{Agradecimientos}

Agradezco a la Fundación de Investigaciones Arqueológicas Nacionales por la financiación de esta investigación. Al ICANH por las fechas de Radio Carbono 14. A los Resguardos de Guachicono, Río Blanco y la comunidad indígena de El Moral, a Albeiro Guerrero y familia, Gilma Melenge, Diva Piamba, Marisol Cerón, comunidad religiosa de Río Blanco, Oscar Jiménez Palechor y familia, y a la comunidad en general por su colaboración y asistencia a los talleres. A Claudia Quiceno y Oscar Burbano por la revisión del manuscrito. A Cristóbal Gnecco y Javier Giraldo por la bibliografía facilitada. De igual forma mis agradecimientos a los evaluadores por sus comentarios. 


\section{Bibliografía}

Anschuetz, Kurt et al. 2001, "An Archeaology of Landscapes: Perspectives and Directions", in: Journal of Archaeological Research, vol. 9, N², pp. 152-197.

Arango, Silvia. 1989, Historia de la arquitectura en Colombia, Universidad Nacional, Bogotá, pp. 19, $23,31$.

Arguello García, Pedro M. 2016, "Arqueología regional en el valle de Tena: un estudio sobre la microverticalidad muisca”, en: Antípoda. Revista. Antropología. Arqueología, No. 25, mayo-agosto, Bogotá, pp. 143-166.

Burbano, Oscar. 2016, "Reconocimiento Arqueológico y narrativas en torno al paisaje de San Lorenzo Cauca", Tesis de pregrado, Universidad del Cauca, Popayán, Colombia.

Buenahora, Gonzalo. 1997, "La república de españoles y los pueblos de indios del Macizo Colombiano durante el período colonial", Tesis de maestría Universidad Nacional, Bogotá, Colombia.

Cadavid, Gilberto y Hernán, Ordoñez. 1992, Arqueología de Salvamento en la Vereda Tajumbina, Municipio de La Cruz (Nariño), FIAN, Fundación de investigaciones arqueológicas, Bogotá, Colombia.

Cardale, Marianne et al. 1992, Calima Diez mil años de historia en el sur de Colombia, Pro-Calima, Bogotá, Colombia.

Cárdenas, Felipe. 1989, "Complejos cerámicos y territorios étnicos en aéreas Arqueológicas de Nariño", en: Boletín de Arqueología, FIAN 4 (3), Bogotá, Colombia.

Cárdenas, Felipe .1996, "Frontera arqueológica VS Frontera etnohistórica. Pastos y Quillacingas en la arqueología del sur de Colombia”, en: Caillavet, Chantall y Ximena Pachón (Comps.) Frontera y Poblamiento estudios de etnohistoria y antropología de Colombia y Ecuador, IFEA, Lima.

Cieza de León, Pedro. 1971, La crónica del Perú. C. XXXIII. CXXXV. Pp. 136-150. Ed, Revista. Ximenez de Quesada.

Céspedes, Antonio. G. 1983, "Relaciones generales del período 1550-1572 Relación De Popayán y el nuevo Reino 1559-1560", en: Revista Cespedesia, INCIVA, Cali, Colombia.

Dollfus, Oliver. 1991, Territorios Andinos Reto y Memoria, IEP, IFEA, Perú.

Gómez Duque, Luis et al. 1981, Arqueología de San Agustín La Estación. FIAN. Banco de la República. Bogotá.

Friede, Juan. 1977, Los Andaki 1538-1947. Historia de la aculturación de una tribu Selvática Fondo de Cultura Económica, México.

Giraldo, Hernando, J. 2007, "Patrones de asentamientos y dinámicas de población en el Alto Caquetá. Una visión arqueológica sobre desarrollos desiguales en una región periférica del sur-occidente colombiano", Tesis de pregrado, Universidad del Cauca, Popayán, Colombia.

Giraldo, Hernando et al. 2016, "Pottery Production and Consumption in the Andean-Amazonian Frontier of Southwestern Colombia (2500-500 B.P.)", Society for American Archaeology 81st Annual Meeting, Orlando, Florida.

Gnecco, Cristóbal. 2003, “Uso Humano del espacio en el Alto Caquetá”, Informe final, Colciencias, Colombia (inédito).

Gnecco, Cristóbal y Patiño, Diógenes. 1986, "Pobladores tardíos del Alto Patía-Guachicono", FIAN, Banco de La República, Bogotá (inédito).

Groot, Ana. M. y Hooykaas, Eva. M. 1991, Intento de delimitación del territorio de los grupos étnicos Pastos y Quillacingas en el Altiplano Nariñense, FIAN, Banco de la República, Bogotá, Colombia.

Gómez, Alba Nelly. 2011, "Hacia una arqueología del paisaje en Colombia: reflexiones necesarias", en: Boletín de Antropología, Universidad de Antioquia, Vol. 25 No 42, Colombia, pp. 231-254.

Herrera, Leonor. 1986, "Las plataformas artificiales en ladera ("tambos"), en la arqueología del suroccidente Colombiano", ICAN, V Congreso Nacional de Antropología.

Humboldt, A. 1991, Viaje a las Regiones Equinocciales del Nuevo Continente, Monte Ávila, Caracas.

IDEAM. 27 de noviembre 2017, Orografía y Geología del área del Macizo Colombiano en: http://documentacion. ideam.gov.co/openbiblio/bvirtual/005192/macizo/pdf/capitulo1.pdf

Langebaek, Carl. H y Dever, Alejandro. 2009, “Arqueología Regional en Tierradentro, Cauca, Colombia”, en: Revista colombiana de antropología, Vol 45 (2), enero-junio, pp. 323-367.

Langebaek, Carl y Carlo Emilio Piazzini. 2003, Procesos de poblamiento en Yacuanquer-Narino: una investigación arqueológica sobre la microverticalidad en los Andes colombianos (siglos X a XVIII d.C.), Interconexión Eléctrica S. A., Bogotá.

Langebaek, Carl. 1995, "Microverticalidad al norte del Ecuador: Una nota crítica sobre su aplicación en Colombia y Venezuela", en: Barona, Guido y Francisco Zuluaga (Eds.) 1r. Seminario de etnohistoria del norte del Ecuador y sur de Colombia.

1992, Noticias de caciques muy mayores: Origen y desarrollo de sociedades complejas en el nororiente de Colombia y el Norte de Venezuela, Santa Fe de Bogotá, Uniandes - Universidad de Antioquia. Colombia. 
1987, "Tres formas de acceso a recursos en territorio de la confederación del Cocuy siglo XVI", Boletín del museo del Oro, 18, Bogotá, pp. 29-45.

Llanos, Héctor. V. 1995, Montículo funerario del alto de Betania (Isnos) Territorialidad y espacio de los muertos en la cultura San Agustín, FIAN, ICAN, Bogotá.

1981, Los Cacicazgos de Popayán a la llegada de Los conquistadores, FIAN, Bogotá.

Márquez, Angela. 2006, "El camino Valencia (Cauca) Quinchana Huila. Pasado y presente de las vías de comunicación en los Andes Colombianos", Tesis de pregrado. Universidad del Cauca, Popayán, Colombia.

Murra, John. V. 1972, El control vertical de un máximo de pisos ecológicos en las sociedades andinas, Huánuco, Perú, Universidad Hermilio Valdizán.

Murra, John. V y Santos, Fernando. 2014, Fronteras y diálogos: Andes y Amazonía, Ministerio de cultura, Lima, Perú. http://centroderecursos.cultura.pe/es/registrobibliografico/fronteras-y-di\%C3\%A1logosandes-y-amazon\%C3\%ADa.

Morlon, Pierre. 1996, Comprender la agricultura campesina en los Andes centrales Perú-Bolivia, IFEA y Centro de estudios regionales Andinos Bartolomé de las casas, Lima, Perú.

Nuñez-Regueiro, Víctor .A. 1984, "El método comparativo en arqueología: Metodología para el estudio de las relaciones en arqueología”, en: Wagner, Erika (Ed.) Relaciones prehispánicas de Venezuela, Fondo Editorial Acta Científica Venezuela, Caracas.

Nuñez, Angelica. 2000, "Uso humano del espacio en el Alto Caquetá. Excavaciones arqueológicas en el Valle de Las Papas", Tesis de pregrado, Universidad del Cauca, Popayán, Colombia.

Ortiz, Rocio. 2001, "Excavación arqueológica en el valle de Santa Rosa", Tesis de pregrado, Universidad del Cauca, Popayán, Colombia.

Orejuela, Maria, E. 2016, "Proyecto Parcelación Campestre Forestal Club Corregimiento de Rozo Municipio de Palmira Valle del Cauca Colombia Fases II y III", Autorizaciones de intervención Arqueológica $\mathrm{N}^{\circ} 4117$ y 4767 ICANH, Informe final, Colombia (inédito).

1998, "Reconocimiento arqueológico del Alto río Guachicono", Tesis de pregrado, Universidad del Cauca, Popayán, Colombia.

Orejas, Almudena. 1991, “Arqueología del paisaje: Historia, problemas y perspectivas”, en: AESPA, vol. 64, CSIC, España, pp. 191-230.

Oberem, Udo. 1981, "El acceso a recursos naturales de diferentes ecologías en la sierra Ecuatoriana. Siglo XVI", en: Oberem, Udo y Segundo Moreno Yánez, Contribución a la Etnohistoria ecuatoriana, Colección Pendoneros, Vol. 20, Instituto Otavaleño de Antropología, Otavalo, Ecuador, pp. 45-63.

Patiño, Diógenes y Gnecco, Cristóbal. 1988, “Ocupación prehispánica del alto Patía”, en: Revista Novedades Colombianas, Universidad del Cauca, No. 5, pp. 72-90.

Patiño, Diógenes et al. 2013, “Arqueología y erupciones volcánicas en épocas prehispánica e histórica en la región del volcán Puracé. Resguardo indígena Puracé”, Informe final, Universidad del Cauca, Popayán, Colombia.

Patiño, Diógenes. 1994, "El valle de Sibundoy y la ceja de montaña andina en el Putumayo: Investigación de arqueología de rescate", en: Revista Cespedesia, INCIVA- Cali, Colombia.

Romoli, Kathleen. 1962, "El suroeste del Cauca y sus indios en el tiempo de la conquista Española”, en: Revista Colombiana de Antropología, Vol. XI, ICAN, Bogotá, pp. 239-297.

Rostworoski, María. 1976, Etnia y sociedad, IEP, Perú.

Rodríguez, Carlos. A. 1992, Tras las huellas del Hombre prehispánico y su cultura en el Valle del Cauca, INCIVA, Fundación Hispanoamericana de Cali Embajada de España, Cali, Colombia.

Ramírez, María. C. 1995, Frontera fluida entre Andes, piedemonte de selva: el caso del valle De Sibundoy, siglos XV-XVII. Instituto Colombiano de cultura hispánica, Bogotá, Colombia.

Ruíz, Ricardo. 2015, "Dinámicas de ocupación del territorio y configuración de Paisaje en Puracé: una interpretación desde la arqueología", Tesis de pregrado, Universidad del Cauca Popayán Colombia.

Salomon, Frank. 1985, "The dinamic potential of the complementrity concept", en: Masuda, S. et al. (Eds.) Andean ecology and civilization, University of Tokio press, Tokio, pp 511-513.

1980, Los señores étnicos de Quito en la época de los Incas, Instituto Otavaleño de Antropología, Otavalo, Ecuador.

Salgado, Héctor et al. 1993, La vivienda prehispánica Calima, INCIVA, Cali. 
Sánchez, Policarpo, Y. 2010, "Las dimensiones del paisaje en Arqueología”, en: MUNIBE (AntropologíaArkeologia), $\mathrm{N}^{\circ}$ 61, San Sebastián, pp. 139-151.

Troll, Carl. 1958, Las culturas superiores Andinas y el medio geográfico, Instituto de Geografía, Universidad Nacional Mayor de San Marcos, Lima.

Tovar, Hermes. 1993, Relaciones y Visitas de los Andes, Siglo XVI, Colcultura - Instituto de Cultura Hispánica, Bogotá.

Uribe, María. V. 1978, “Asentamientos prehispánicos en el altiplano de Ipiales, Colombia”, en: Revista Colombiana de Antropología, Vol. 21, pp.57-195.

Vargas, Patricia. 1996, Los Embera y los Cuna: Impacto y reacción ante la ocupación española Siglos XVI y XVII, Instituto Colombiano de Antropología. 